\title{
Financiamiento de los procesos electorales. Examen de la Ley 19.884 sobre Transparencia, Límite y Control del Gasto Electoral*
}

\author{
Gladys Camacho Cepeda**
}

\begin{abstract}
RESUMEN
La autora sostiene que el sistema de financiamiento de las campañas electorales no responde eficazmente a los objetivos de "Transparencia, Limite y Control del Gasto Electoral" que dan nombre a la ley. Un sistema de financiamiento que entrega al electorado poca información acerca de los donantes y donatarios es fundamento para la desconfianza en las instituciones, lo que termina debilitando la democracia. La finalidad del presente estudio es examinar el modelo estructurado por el legislador y contrastarlo con su aplicación. Igualmente, busca mostrar que el sistema vigente propicia una desmesurada asimetría de la información, al igual que no permite el control de los límites legales de financiamiento.
\end{abstract}

Financiamiento electoral - transparencia electoral - rendición de cuentas electorales

\section{Financing of elections. Review of Law $N^{\circ} 1984$ on Transparency, Limit and Control Election Spending}

\begin{abstract}
The author argues that the system of financing of the electoral campaigns do not effectively respond to the objectives of "Transparency, Limit and Control of the Electoral Cost" that give name to the law. A financing system that gives to the electorate little information about the donors and donees is foundation for mistrusts into institutions which ends up weakening democracy. The purpose of this study is to examine the model structured by the legislature and contrast it with its application. It also seeks to show that the current system encourages a disproportionate asymmetry of information as does not allow control of legal funding limits.
\end{abstract}

Election financing - electoral transparency - electoral accountability

* Siglas empleadas: CPR: Constitución Política de la República; Ley 18.700: Ley Orgánica Constitucional sobre Votaciones Populares y Escrutinios; Ley 19.884: Ley sobre Transparencia, Limite y Control del Gasto Electoral; Ley 18.556: Ley Orgánica Constitucional sobre Sistema de Inscripciones Electorales y Servicio Electoral; BCN: Biblioteca del Congreso Nacional; SERVEL: Servicio Electoral; Consejo Asesor Presidencial Anticorrupción: Consejo Anticorrupción; TRICEL: Tribunal Electoral; U.F.: Unidad de Fomento; USD: Dólar norteamericano.

** Profesora Asociada de Derecho Administrativo, responsable de la Cátedra OCDE-Ministerio de Relaciones Exteriores "Probidad y Transparencia Públicas", además de Coordinadora del Área de Derecho Administrativo del Departamento de Derecho Público de la Facultad de Derecho de la Universidad de Chile. Doctora en Derecho por la Universidad Carlos III de Madrid. Magíster en Administración Pública por la Universidad de Alcalá (Madrid). Correo electrónico: gcamacho@ derecho.uchile.cl.

Artículo recibido el 10 de noviembre de 2014 y aceptado para su publicación el 28 de agosto de 2015. 


\section{INTRODUCCIÓN}

$\mathrm{E}$ n el mundo contemporáneo el costo de las elecciones y de las campañas políticas alcanza cifras cada vez más elevadas. En este marco es insoslayable que el financiamiento de la política emplea fondos privados, lo que multiplica los riesgos de corrupción, pues aunque el uso de recursos económicos es indispensable para la competencia política no deja de ser un factor potencialmente distorsionador de los procesos eleccionarios.

La transición democrática en Chile ha costado un gran esfuerzo de consenso y de articulación política cuyo elemento de cohesión inicial fue el dejar definitivamente atrás la dictadura militar de Pinochet, es decir, neutralizar los riesgos a un retorno autoritario con intervención militar. Tras 5 lustros de gobiernos democráticos tal objetivo parece cumplido, el escenario social también ha cambiado caracterizándose por crecientes demandas sociales que imponen nuevas prioridades a los partidos (mejor dicho conglomerados políticos), cuya atención les resulta obligatoria a fin de seguir manteniéndose en la conducción del país, bien sea desde el gobierno o desde la oposición. Los dos grandes bloques políticos, la "Alianza por Chile”, integrada por los partidos más representativos de la derecha chilena ${ }^{1}$, y la "Concertación de Partidos por la Democracia", frente de partidos que aglutinó a los opositores a Pinochet ${ }^{2}$, hoy renombrada "Nueva Mayoría” - por la significativa incorporación del Partido Comunista-, conglomerado actual en el gobierno, enfrentaron la reforma del sistema electoral binominal instaurado junto con la Constitución Política de 1980, lo que constituyó la reforma política más difícil de consolidar.

Si bien durante la primera centuria de la vida republicana los procesos electorales estuvieron repletos de vicios: cohecho, voto de difuntos, suplantación de electores y falsificación de escrutinios. A medida que la institucionalización de la República avanzó las reformas electorales básicamente orientadas a democratizar el voto ${ }^{3}$ han ido

${ }^{1}$ La Alianza por Chile es una coalición de partidos integrada por la Unión Demócrata Independiente y Renovación Nacional que surgió en 1989 para enfrentar las contiendas electorales que aunque sin estar exenta de dificultades básicamente se sigue manteniendo.

${ }^{2}$ La Concertación de Partidos por la Democracia está conformada por el Partido Demócrata Cristiano, el Partido Socialista, el Partido por la Democracia y el Partido Radical Social Demócrata, gobernando durante cuatro períodos presidenciales consecutivos entre 1990 y 2010.

${ }^{3}$ La Constitución de 1833 estableció el "voto censitario", por el que solo los hombres casados mayores de 21 años y los solteros mayores de 25 que tuvieran una renta determinada, bienes inmuebles y supieran leer y escribir podían votar. La primera ampliación sustantiva del voto se realizó en 1874, pues si bien se mantuvieron los rangos etarios y la exigencia de alfabetización, la ley de ese año eliminó el requisito de renta, estableciéndose el voto secreto. En 1888, el voto se niveló a todos los hombres mayores de 21 años alfabetizados. En 1935 fue la primera vez que las mujeres ejercieron el derecho al voto en elecciones municipales, sin embargo, hubo de esperarse hasta 1949 para que se reconociera el derecho a las mujeres a participar en las elecciones de parlamentarios y presidenciales, lo que aconteció recién en 1952. Otras reformas que ampliaron el voto fueron las de 1961 en donde se incorporaron los ciegos al padrón electoral y en 1970, bajo la Ley 17.284 de reforma constitucional se reconoció el voto a todos los chilenos partir de los 18 años de edad que estén inscritos en el padrón electoral. Vid. BCN, Elecciones, sufragio y democracia 
construyendo un sistema electoral no exento de cuestionamientos, en los que la élite política controla las instituciones de una manera no inclusiva, surgiendo pocos incentivos para cambiar estas estructuras.

Los reclamos contemporáneos al sistema electoral estuvieron, especialmente, referidos a las limitaciones a una amplia representación democrática en el Congreso que producía el sistema binominal, pues su efecto más inmediato era la marginación de las cámaras parlamentarias de los partidos menores y candidatos independientes que no eran capaces de incorporarse a alguna coalición, favoreciéndose una suerte de bipartidismo sobre la base de dos bloques: la "Alianza por Chile" y la "Nueva Mayoría” (ex-Concertación). La Ley 20.840, vigente desde mayo pasado, ha sustituido el sistema binominal por un sistema electoral que busca una mayor proporcionalidad basado en el coeficiente D'Hont como método de asignación parlamentaria ${ }^{4}$. Los motivos que impulsaron la reforma los podemos encontrar en el Mensaje de la Presidenta ${ }^{5}$, sin embargo, aún se discute si la reforma aprobada ha alcanzado superar el anterior sistema de manera satisfactoria.

en Chile (1810-2012). Disponible en: http://www.memoriachilena.cl/602/w3-article-3382.html [consulta: 2 de junio de 2014].

${ }^{4}$ Los principales cambios de esta reforma tienen relación con:

- El aumento del número de parlamentarios, subiendo de 120 a 155 los diputados y en el caso de los senadores, estos suben de 38 a 50 . Esto supone un aumento total de 12 senadores y 35 diputados, lo que significa 47 parlamentarios más.

- La proporcionalidad se basa en que los cupos se obtienen según la cantidad de votos que obtiene cada partido o pacto de partidos o asociación con candidaturas independientes.

- Se establecen cupos impares en varias de las circunscripciones lo que impide un escenario de empate.

- Se impulsa la paridad de género en el Congreso imponiendo que las candidaturas que presenten las listas al Senado o a la Cámara no pueden estar conformadas por un porcentaje superior al $60 \%$ bien sea por candidatos hombres ni candidatas mujeres.

- Se rebajan las exigencias para la creación de nuevos partidos. Basta con que se hubieren constituido legalmente en al menos una de las regiones y para inscribir un partido, se reduce el coeficiente de “0,5" a "0,25" de las firmas de las personas que votaron en la elección anterior.

- En el mapa político electoral hay grandes cambios. Para la Cámara de Diputados se crea un nuevo mapa electoral estableciéndose 28 distritos (antes habían 60), son distritos mucho más grandes que acumulan muchas más comunas, no sucede lo mismo en las circunscripciones electorales senatoriales, pues aquí hay una identidad con las mismas 15 regiones que actualmente tenemos.

${ }^{5}$ El Mensaje Presidencial con el que fue remitido el proyecto que se transformaría en la Ley 20.840, resume en su título los motivos para impulsar la reforma, los que están relacionados fundamentalmente con los defectos de representatividad: "Sustitu[ir] el Sistema Electoral Binominal por un Sistema Electoral proporcional, inclusivo y Fortalece[r] la Representatividad del Congreso Nacional. De este modo el Mensaje expresaba que "La existencia del sistema electoral binominal es uno de los factores que afecta negativamente la representatividad de nuestro Parlamento". En consecuencia, el proyecto responde a seis objetivos a los que debe responder el cambio de sistema electoral: 1. Reducir la desigualdad del voto; 2. Permitir la representación e inclusión de todas las corrientes significativas; 3. Aumentar la competitividad e incertidumbre respecto de quienes resulten elegidos; 4) Facilitar la expresión de la mayoría y la representación de las minorías; 5) Promover un Congreso que refleje la diversidad de la sociedad; y 6) Evitar que queden fuera candidatos con grandes votaciones. Vid. BCN, Historia de la Ley 20.840 Sustituye el sistema electoral binominal por uno de carácter proporcional inclusivo y fortalece la representatividad del Congreso Nacional, 2015, pp. 3-8. Disponible en: http://www.leychile.cl/Consulta/portada_hl [consulta: 5 de agosto de 2015]. 
Si bien nuestro sistema económico ha sido exitoso en producir el crecimiento productivo esto ha tardado en traducirse en instituciones políticas inclusivas que alejen el peligro que produce la alta concentración del poder, situación que siempre tiende a desbordarse. La ajenidad y desconfianza con la que la sociedad percibe las instituciones políticas y a sus representantes son consecuencia de una sociedad extremadamente oligárquica, poco cohesionada, que genera escasas oportunidades para quienes no tienen las conexiones sociales adecuadas ${ }^{6}$. Lograr transformar esta situación se constituye en el desafío para nuestro sistema político y la viabilidad de convertirnos en un país que traspase el umbral del subdesarrollo.

El sistema binominal recientemente reformado constituyó una traba insalvable durante los primeros seis gobiernos democráticos, pero los cambios al sistema electoral introducidos por la Ley 20.840 suscitan serias dudas sobre si solucionan satisfactoriamente la críticas que motivaron la reforma ${ }^{7}$.

La regulación del financiamiento público a los procesos electorales surgió asociado al escándalo de corrupción política más grave que ha tenido un gobierno democrático a propósito del caso denominado como "MOP-GATE", ocurrido durante el gobierno del expresidente Ricardo Lagos Escobar, que desembocó en la agenda modernizadora suscrita por la oposición y el gobierno, la que contemplaba, entre otras importantes medidas legislativas, el envío del proyecto que se convertiría en la Ley 19.884 sobre Transparencia y Límite al Gasto Electoral, sancionada en 2002, que venía a suplir la completa desregulación que exis(tía) sobre la materia y la inexistencia de normas mínimas de transparencia ${ }^{89}$. En este contexto, ciertamente, esta medida constituyó un avance.

\footnotetext{
${ }^{6}$ A este respecto, las declaraciones de Robinson son muy ilustrativas: Si te fijas en Chile, por ejemplo,
} el ingreso per cápita es el doble del de Colombia. ¿A qué se debe? A que tiene un Estado centralizado eficaz, el cual tiene la capacidad de asignar la renta de los recursos nacionales a actividades convenientes. El Estado chileno puede construir vías y escuelas y garantizar el orden. Pero Chile tiene una sociedad extremadamente oligárquica. El 50\% de los ministros en el gabinete del presidente Piñera estuvieron en cuatro colegios católicos de hombres en Santiago. El $50 \%$ de los presidentes ejecutivos de las cien empresas más importantes de Chile estudiaron en los mismos cuatro colegios. Chile tiene un Estado centralizado eficaz, pero no una sociedad inclusiva, porque las conexiones sociales y los contactos a nivel de la élite son increíblemente importantes para conseguir oportunidades. Si no eres parte del club, no estás en nada en Chile. Ese es un gran impedimento”, en Acosta, B., “¿Por qué fracasan los países?”, entrevista a J. Robinson, en Boletín Koyuntura, Instituto de Economía de la USFQU No 41, Año 5, p. 3. Disponible en: http://www. usfq.edu.ec/publicaciones/koyuntura/Documents/koyuntura_2014-41.pdf [consulta: 11 de junio de 2014 ].

7 A este respecto se puede consultar Luna, J.P., ¿Por qué es difícil pronosticar los efectos del cambio del sistema electoral?”. Disponible en: http://politicaspublicas.uc.cl/seminario/seminario-fin-al-binominal-cuantocambia-el-escenario/ [consulta: 5 de agosto de 2015] y San Martín, E., Sistema Binominal versus Coeficiente D’Hont ¿Cuán diferentes son como métodos de asignación parlamentaria?. Disponible en: http://politicaspublicas. uc.cl/seminario/seminario-fin-al-binominal-cuanto-cambia-el-escenario/ [consulta: 5 de agosto de 2015 ].

${ }^{8}$ Afirmación del Mensaje Presidencial con el que se remitió el proyecto de ley que daría lugar a la Ley 19.884, en BCN, Historia de la Ley 19.884 sobre Transparencia, límite y control de gasto electoral, Valparaíso, 2003, p. 8.

${ }^{9}$ Navia asocia la crisis política que generó este caso junto con el denominado "Caso Coimas" a la generación de una coyuntura favorable para lograr avances en materia de regulación del Financiamiento de la Política, en Modernización del Estado y Financiamiento de la Política: Una Crisis que se Transformó en Oportunidad, en Stefoni, C. (editora), Chile 2003-2004. Los Nuevos Escenarios (inter)nacionales, Flacso, Chile, 2004. 
Desde entonces, tenemos una regulación del financiamiento no de los partidos políticos o de la actividad política en general sino específicamente del gasto de campañas incurrido en el marco de votaciones populares nacionales, regionales y municipales, cuyas particularidades esenciales se analizarán en el presente trabajo. La Constitución Política no consagra un reconocimiento del valor y función que cumplen los partidos políticos en el sistema democrático ${ }^{10}$, más bien la atención que les presta está orientada a la fijación de los límites en que debe desarrollarse su actuación como consecuencia del ejercicio del derecho de asociación (artículo $19 \mathrm{~N}^{\circ} 15$ CPR) y en constituir garantías para que en los procesos electorales sus miembros no tengan ventajas frente a los independientes (artículo 18 CPR). En consonancia con esta omisión, la Carta Política solo ordena al legislador regular la financiación de los procesos electorales y plebiscitarios. Eso sí, prohíbe a los partidos políticos recurrir a fuentes de financiamiento de cualquier tipo (dineros, bienes, donaciones, aportes y créditos) de procedencia extranjera (artículo $19 \mathrm{~N}^{\circ} 15 \mathrm{CPR}$ ).

Con el objetivo de garantizar la plena igualdad entre los independientes y los miembros de partidos políticos, tanto en la presentación de candidaturas como en la participación de los procesos electorales, la Constitución Política ordena que el legislador establezca un sistema de financiamiento, transparencia, límite y control del gasto electoral, lo que en 2002 se dio cumplimiento con la promulgación de la Ley 19.884 sobre Transparencia y Límite al Gasto Electoral, cuyas características básicas pueden sintetizarse en las siguientes:

- Fija los límites al gasto electoral para candidatos y partidos políticos.

- Establece multas en caso que los límites fijados sean superados.

- Define características e impone límites para los aportes privados individuales.

- Instituye el otorgamiento de financiamiento público a los gastos de campaña.

- Establece el procedimiento para investigar las posibles infracciones a la normativa de control del gasto electoral.

Si bien la realidad nos evidencia que los eventos electorales requieren de financiamiento, por lo que el aporte de dinero público a este propósito se entiende como una inversión en la democracia, el modelo de financiamiento contenido en la Ley 19.884 no satisface eficientemente aspectos como el de transparencia, rendición de cuentas, control del gasto electoral, objetivos declarados en la ley, lo que se desprende del examen que seguidamente se hace del modelo estructurado por el legislador, evidenciando sus debilidades regulatorias y contrastándolo con su aplicación.

${ }^{10}$ Una de las consecuencias de la postguerra fue el reconocimiento constitucional de los partidos políticos en el ámbito europeo. A manera de ejemplo se puede citar el artículo 6 de la Constitución española que declara: Los partidos políticos expresan el pluralismo político, concurren a la formación y manifestación de la voluntad popular y son instrumento fundamental para la participación política.... Como señala Santano, ello ha servido de fundamento para que se establezcan sistemas de financiación con aportes del erario público a dichas organizaciones, existiendo hoy muchos ejemplos de sistemas mixtos de financiación con predominio de financiación pública. Vid. Una breve retrospectiva sobre la financiación de los partidos políticos en Alemania, en Revista Paraná Eleitoral v. 2 No 2, 2013, pp. 216. 


\section{De LOS OBJETIVOS DE LA REGULACIÓN Y SUS CARACTERÍSTICAS ESENCIALES}

Si nos remitimos al Mensaje Presidencial con que se envió el proyecto de ley de límite al gasto electoral, el propósito perseguido fue regular de un modo acabado los sistemas de financiamiento de campañas electorales, procurando que todos los candidatos y partidos participen en los actos electorales en un mínimo pie de igualdad, todo ello de conformidad con la primera disposición constitucional que obliga al Estado a asegurar la participación en la vida nacional con igualdad de oportunidades ${ }^{11}$. La iniciativa presidencial partía de la convicción que estaba abordando un tema de gran sensibilidad en nuestro sistema político, pero que era crucial para evitar el deterioro del mismo por la influencia desmedida del dinero de cuya tendencia no estamos exentos, habiendo tenido variadas experiencias recientes ${ }^{12}$. Así, el financiamiento de la actividad política se constituye en una fuente principal de corrupción de los sistemas políticos que terminan degradando nuestra democracia y la legitimidad de nuestras instituciones ${ }^{13}$.

Las disposiciones legales relacionadas con la correcta aplicación de la regulación acerca del financiamiento de las campañas políticas son las siguientes:

- Constitución Política de la República, artículos 18 y 19 Nº 15.

- Ley 18.700, Orgánica Constitucional de Votaciones Populares y Escrutinios.

- $\quad$ Ley 19.884, sobre Transparencia, Límite y Control del Gasto Electoral ${ }^{14}$.

- Ley 18.695, Orgánica Constitucional de Municipalidades

- $\quad$ Ley 18.603, Orgánica Constitucional de los Partidos Políticos

${ }^{11}$ El Mensaje Presidencial, además, desglosaba el objetivo general en los siguientes objetivos específicos de la regulación que se proponía, consistentes en: 1) Fijar montos máximos de gastos en campañas electorales para garantizar la igualdad de oportunidades económicas de los candidatos y partidos políticos que los postulen; 2) Regular el financiamiento privado de las campañas electorales con el objeto de conocer los orígenes de esos recursos, para garantizar la independencia de quienes ocupen dichos cargos; 3) Externalizar la administración de los recursos y gastos electorales, encargando de ello a las personas naturales que designen los candidatos y partidos políticos, a fin de establecer claramente las responsabilidades en el cumplimiento de la ley; 4) Crear un completo sistema de control externo del origen de los recursos empleados en las campañas electorales y de los gastos de propaganda evitando los riesgos de corrupción; y 5) Consagrar un mecanismo de publicidad de los recursos y gastos con el fin de garantizar la necesaria transparencia. Vid. BCN, Historia de la Ley 19.884..., op. cit., p. 8.

12 Entre los casos más recordados se encuentran los ocurridos en el gobierno del expresidente Ricardo Lagos, denominados casos "Coimas" y "MOP-GATE", que conllevaron en el primero de los mencionados el desafuero de cinco diputados y la condena de un subsecretario; y en el segundo caso, la condena del exministro de Obras Públicas, señor Carlos Cruz.

13 Según la encuesta "Barómetro de la Política Chilena" del Centro de Estudios de la Realidad Contemporánea, de enero de 2014 , los partidos políticos han perdido casi totalmente su prestigio, apenas el $10 \%$ confía en ellos, por su parte solo el 17\% cree en la Cámara de Diputados; y 20\% confía en el Senado. Vid. Centro de Estudios de Realidad Contemporánea, Barómetro de la Política, CERC. 2014. Disponible en: http://www.cooperativa.cl/noticias/site/artic/20140123/asocfile/20140123112537/20140123102341_ barometro_de_la_politica_diciembre_enero_2014.pdf [consulta: 2 junio 2014 ].

${ }^{14}$ Esta disposición central en materia de gasto electoral se ha modificado en 5 oportunidades en virtud de las Leyes 19.963 y 19.964 ambas publicadas en D.O. de 26 de agosto de 2004, la Ley 20.053 publicada en D.O. de 6 de septiembre de 2005, la Ley 20.568 en D.O. de 31 de enero de 2012 y Ley 20.568 en D.O. DE 19 de junio de 2013. 
Como se ha advertido en Chile no tenemos una regulación general de financiamiento de la política o de los partidos políticos, sino que esta se circunscribe al gasto incurrido por los partidos políticos y candidatos, en el marco de los procesos eleccionarios contemplados en la Ley 18.700, sobre Votaciones Populares y Escrutinios y la Ley 19.695, Orgánica Constitucional de Municipalidades.

Según el Instituto Interamericano de Derechos Humanos puede definirse como campaña electoral al conjunto de actividades organizativas y comunicativas realizadas por los candidatos y partidos que tienen como propósito captación de votos ${ }^{15}$. Concordantemente, el artículo 30 de la Ley 18.700 define el término propaganda electoral como aquella dirigida a inducir a los electores a emitir su voto por candidatos determinados o a apoyar alguna de las proposiciones sometidas a plebiscito. Está claro que el objetivo de una campaña es lograr influir en las decisiones de los votantes de cara a unas elecciones y que esto no se realiza de forma fortuita sino que es un proceso planificado, y hoy controlado. En la actualidad las campañas electorales involucran mensajes, imágenes, pintura, carteles, afiches ${ }^{16}$, señales, medios de comunicación de masas, y especialmente las redes sociales y otras plataformas interactivas que permite internet. La Ley 18.700 , en el artículo 30 ya citado, solo autoriza a realizar propaganda electoral en las oportunidades autorizadas por la ley. En nuestro caso la ley define solo el espacio temporal que puede comprender una campaña electoral y los gastos electorales admisibles. Así, en teoría, no se podrían realizar actividades orientadas a promocionar un candidato con anticipación al inicio de la fecha autorizada y solo son admisibles aquellos gastos directamente relacionados con la campaña electoral y no con gastos corrientes u ordinarios de la actividad política. El hecho de que estos gastos (ilegales) se produzcan no es en consecuencia por falta de prohibición, sino lo que debilita la anotada proscripción es que la institucionalidad electoral carece de recursos jurídicos, personales y materiales adecuados para su fiscalización ${ }^{17}$. El artículo $3^{0}$ de la Ley 19.884 determina que se entenderá por período de campaña electoral, como aquel comprendido entre el día que venza el plazo para declarar candidaturas y el día de la elección respectiva. En la práctica, la forma de establecer el inicio del período de campaña electoral más sencilla ha sido asociándolo a la autorización contenida en la Ley 18.700, la que

${ }^{15}$ Instituto Interamericano de Derechos Humanos, "Campaña Electoral” por Tuesta Soldevilla, F., en Diccionario Electoral. Disponible en: http://www.iidh.ed.cr/comunidades/redelectoral/docs/red_diccionario/ campana\%20electoral.htm [consulta: 2 de junio de 2014 ].

${ }^{16}$ En relación con las pinturas, carteles y afiches adheridos a muros exteriores y cierros privados, estos son admitidos siempre que se cuente con la autorización del propietario, poseedor o mero tenedor del inmueble.

${ }^{17} \mathrm{Al}$ respecto es expresivo el diagnóstico: Las normas y leyes, por bien diseñadas e intencionadas que sean, no logran tener el efecto deseado si no exiten instituciones capaces de fiscalizar su cumplimiento y penalizar cuando son vulneradas. La eficacia de los organismos fiscalizadores determina la solidez y profundidad del sistema democrático. La debilidad en el actual sistema de control, las bajas sanciones e incapacidad para imponerlas han ido generando riesgos para la probidad, capturando agendas colectivas para intereses particulares, distorsionando la equidad en la competencia electoral y debilitando el carácter programático y colectivo de los partidos políticos. Vid. Consejo Asesor Presidencial contra los Conflictos de Interés, el Tráfico de Influencias y la Corrupción, Informe Final, Santiago, abril 2015, p. 65. Disponible en: http://consejoanticorrupcion.cl/informe/ [consulta: 5 de agosto de 2015]. 
solo permite realizar propaganda electoral por medio de prensa, radioemisoras y canales de televisión, a partir de 30 días antes de la elección (art. 30 inciso $4^{\mathrm{o18}}$ ).

Igualmente, nuestra legislación no admite algo que, sin embargo, es práctica generalizada, cual es la denominada precampaña electoral ${ }^{19}$, en consecuencia, la normativa electoral es contraria a ella ${ }^{20}$. De un lado, la Ley 18.700 señala que la campaña electoral solo puede realizarse en las oportunidades y formas establecidas por la ley; por su parte, si bien la Ley 19.884 no establece una sanción propiamente tal a la vulneración de esta disposición, sí contiene una consecuencia jurídica negativa para el infractor, puesto que los gastos incurridos con anterioridad al período electoral se reputan como gastos electorales a efectos del límite de gasto autorizado para la correspondiente elección (art. $3^{\circ}$ Ley $\left.19.884^{21}\right)$. Igualmente, el inciso $3^{\circ}$ del artículo 5 de la Ley 19.884 establece una presunción de gasto electoral que cubre a las erogaciones que superen al promedio de gastos incurridos por el respectivo partido durante los seis meses anteriores al inicio del período de campaña electoral con independencia de cualquiera haya sido su fecha de contratación o pago efectivo y aun cuando se encuentren pendientes de pago. Para estos efectos, los partidos políticos deben informar mensualmente al SERVEL de sus gastos ordinarios de funcionamiento durante los seis meses previos al inicio del período de campaña electoral y durante este ${ }^{22}$.

${ }^{18} \mathrm{El}$ inciso $4^{\circ}$ del artículo 30 de la Ley 18.700, a la letra dispone: La propaganda electoral por medio de la prensa, radioemisoras y canales de televisión solo podrá efectuarse desde el trigésimo y hasta el tercer día anterior al de la elección o plebiscito, ambos días inclusive.

19 Para muestra basta solo recordar el reciente escándalo que involucró al ex-Ministro del Interior Rodrigo Peñailillo, relacionado con recursos para solventar gastos de precampaña de la entonces responsable de ONU Mujeres y actual Presidenta de la República, Michelle Bachelet. Vid., La Tercera, Martelli dice que asesorías de Peñailillo fueron encargadas por el mismo exministro, noticia del 20 de junio de 2015. Disponible en: http://www.latercera.com/noticia/politica/2015/06/674-635224-9-martelli-dice-que-asesorias-de-penailillofueron-encargadas-por-el-mismo-ex.shtml [consulta el 10 de agosto de 2015] y TVN 24Horas, Presidente de la CPC en Estado Nacional: Hay que diferenciar las actitudes del empresariado, en programa Estado Nacional del 28 de septiembre de 2014. Disponible en: http://www.24horas.cl/programas/estadonacional/presidentede-la-cpc-en-estado-nacional-hay-que-diferenciar-las-actitudes-del-empresariado-1430878 [consulta: 10/08/2015]. Otros casos importantes son los ya conocidos como "PENTA" y "SQM", el primero, vinculado al financiamiento político de candidatos de la oposición, y el segundo por su transversalidad; la figura del cohecho es la que mejor parece encajarlo, pero aún son casos que se están investigando.

${ }^{20}$ El Consejo Anticorrupción, aplicando el principio de realidad propone establecer un período de precampañas que obligue a declarar los ingresos y gastos al SERVEL, en Informe Final, op. cit., p. 75.

${ }^{21} \mathrm{El}$ inciso $3^{\circ}$ del artículo $3^{\circ}$ de la Ley 19.884 prescribe que: Los candidatos no podrán realizar gastos electorales de propaganda dirigida directa o indirectamente a promover el voto, antes del plazo que esta ley establece $y$ especialmente 30 días antes de su vencimiento. Si así fuere, comprobado por el Servicio Electoral después de investigar denuncias fundadas, dichos gastos se computarán dentro del monto establecido como límite en el artículo $4^{\circ}$ de esta ley.

22 Del mismo modo, si bien la legislación electoral no establece cuáles son los medios lícitos para hacer campaña electoral estos se deducen de los recursos que la ley proscribe emplear y de los conceptos que la normativa acepta como gasto electoral. En relación con los primeros, la Ley 18.700 proscribe realizar "propaganda electoral en cinematógrafos y salas de exhibición de videos y la que en cualquier lugar o forma se realice por altoparlantes fijos o móviles, con la única excepción de la transmisión de discursos pronunciados en concentraciones públicas" (artículo 30 inciso $6^{\circ}$ ). Igualmente, se encuentra proscrita si la propaganda electoral se realiza mediante elementos que cuelgan sobre la calzada o que se adhieran de cualquier modo al 
Concordantemente con lo señalado, el artículo $2^{\circ}$ de la Ley 19.884 permite el eventual reembolso de los siguientes gastos incurridos durante el período de campaña electoral por los candidatos o partidos políticos en:

- Propaganda y publicidad dirigida, directa o indirectamente, a la promoción del voto para un candidato o candidatos determinados, cualquiera sea el lugar, la forma y medio que se utilice.

- Encuestas acerca de materias electorales o sociales.

- Arrendamientos de bienes muebles e inmuebles destinados al funcionamiento de los equipos de campaña o a la celebración de actos de proselitismo electoral.

- Pagos efectuados a personas que presten servicios a las candidaturas.

- Gastos realizados para el desplazamiento de los candidatos, de los dirigentes de los partidos y de las personas que presten servicios a las candidaturas, así como para el transporte de implementos de propaganda y para la movilización de personas con motivo de la campaña; y.

- Otros gastos señalados en la ley ${ }^{23}$.

Particularmente corresponde a Carabineros de Chile la responsabilidad de fiscalizar el cumplimiento de las prohibiciones de la publicidad electoral, salvo en lo que se refiere a la prensa, radio y televisión. En su caso, luego de retirar la propaganda que infrinja la ley, Carabineros deberá dar cuenta al juez de policía local respectivo. Del mismo modo, las municipalidades deben proceder a retirar u ordenar el retiro de la propaganda electoral infractora.

Un aspecto significativo está referido a las restricciones legales establecidas para la calidad de aportante, pues de acuerdo con los artículos $24^{\circ}, 25^{\circ}$ y $26^{\circ}$ de la Ley 19.884 no pueden ser donantes de campaña electoral:

tendido eléctrico o igualmente involucra componentes y equipamiento urbanos, tales como calzadas, aceras, puentes, parques, postes, fuentes, estatuas, jardineras, escaños, semáforos y quioscos. Por su parte, los recursos de campaña que la Ley 19.884 admite en términos generales son: publicidad y propaganda realizada por cualquier medio y forma; constitución de equipos de campaña, realización de actos proselitistas, realización de encuestas, obtención de financiamiento mediante préstamos en el sistema financiero, realización de donaciones para patrocinar actos culturales, deportivos u otros, empleo de trabajo voluntario.

${ }^{23}$ Otros gastos que están legalmente autorizados son:

- El costo de los endosos y los intereses, el impuesto de timbre y estampillas, los gastos notariales y, en general, todos aquellos gastos en que haya incurrido por efecto de la obtención de los créditos recibidos para la campaña electoral, devengados hasta la fecha en que se presente la cuenta general de ingresos y gastos correspondientes.

- Las erogaciones o donaciones realizadas por los candidatos a organizaciones o personas naturales o jurídicas, mediante el patrocinio de actos culturales, deportivos o de cualquier otro tipo a celebrarse dentro del ámbito territorial respectivo.

- Gastos menores y frecuentes de campaña, tales como alimentación de personas, mantención de vehículos o de las sedes u otros similares.

- Gastos por trabajos de campaña, proporcionados por personas con carácter voluntario, debidamente avaluados con criterios objetivos. 
- Las personas naturales o jurídicas extranjeras, con la sola excepción de los extranjeros habilitados para ejercer el derecho al sufragio en Chile.

- Los órganos de la Administración del Estado, empresas del Estado o empresas o instituciones en que este tenga participación directa o indirectamente.

- Las personas jurídicas que reciban subvenciones o aportes del Estado, si el aporte representa más del $15 \%$ de sus ingresos en cualquiera de los últimos dos años.

- Las personas jurídicas que contraten con el Estado o sus órganos la provisión de bienes, prestación de servicios o la realización de obras, si los montos a que ascendieren los contratos respectivos representan un porcentaje superior al $40 \%$ del total de su facturación anual en el respectivo año calendario o en alguno de los dos años calendarios precedentes En el caso de que estas personas jurídicas se encuentren participando de un proceso licitatorio durante la campaña electoral será causal de eliminación o de término anticipado del contrato, siempre y cuando el monto de la licitación represente un porcentaje superior al $40 \%$ del total de su facturación anual en cualquiera de los dos años calendarios anteriores.

- Las personas jurídicas de derecho público o privado sin fines de lucro.

Un dato que llama la atención es que el SERVEL no ha investigado ni ha aplicado sanciones por las infracciones listadas anteriormente. Esto es así, no obstante, que al menos el cumplimiento de la prohibición referida a empresas que contratan con el Estado merece ser cautelado y que existen dudas que no se haya traspasado esta norma.

Otra importante arista en la regulación del financiamiento del gasto electoral son los límites establecidos según el cargo al que el candidato aspire en la respectiva campaña. Así, la candidatura a senador tiene uno de los topes más altos junto con la candidatura a Presidente de la República, por cuanto sus circunscripciones electorales son más amplias, les siguen la candidatura a diputado, consejero regional y finalmente la candidatura a alcalde y concejal. En el siguiente cuadro podemos resumir los correspondientes límites establecidos en el artículo $4^{\circ}$ de la Ley 19.884 que variarán según la UF con la que se calcula.

Además, la Ley 19.884 señala como límite de gasto electoral de los partidos políticos el equivalente a un tercio de la suma total de los gastos electorales permitidos a sus candidatos, incluidos los independientes que vayan en pacto o subpacto con él (inciso $1^{\circ}$ del artículo 5). Cuando dos o más partidos políticos se presenten en pactos o subpactos, el referido tercio de gastos autorizados se distribuirá a prorrata de los candidatos respectivos, incluidos los independientes, entre los partidos que integran el pacto o, en su caso, el subpacto (inciso $3^{\circ}$ del artículo $5^{\circ}$ ).

\section{TIPOS DE FINANCIAMIENTO ELECTORAL Y OBLIGACIONES DE TRANSPARENCIA}

La regulación respecto de los tipos de financiamiento electoral admitidos es un aspecto crucial para la efectividad de los propósitos de transparentar, limitar y controlar el gasto electoral, objetivos que claramente se orientan a la preservación y saneamiento 


\section{Cuadro 1 \\ LÍMITES DEL GASTO ELECTORAL}

\begin{tabular}{|c|c|c|}
\hline Candidatura & Límite fijo en U.F. ${ }^{23}$ & Límite variable en U.F. \\
\hline Senador & 3.000 & $\begin{array}{l}\text { - } 1^{\text {ros }} 200.000 \text { electores x } 0,04 \text { U.F. } \\
\text { - } 2^{\text {dos }} 200.000 \text { electores x 0,03 U.F. } \\
\text { Restantes electores x 0,02 U.F. }\end{array}$ \\
\hline Diputado & 1.500 & 0,03 U.F. $\times \mathrm{N}^{o}$ de electores del distrito electoral \\
\hline Alcalde & 120 & 0,03 U.F. $\mathrm{x} \mathrm{N}^{\circ}$ de electores de la comuna \\
\hline Concejal & - & $1 / 2$ de lo permitido gastar al candidato a alcalde \\
\hline $\begin{array}{l}\text { Consejero Regional } \\
\text { (circunscripción provincial) }\end{array}$ & 700 & $\begin{array}{l}\text { - } 1^{\text {ros }} 200.000 \text { electores x } 0,02 \text { U.F. } \\
\text { - } 2^{\text {dos }} 200.000 \text { electores x 0,015 U.F. } \\
\text { Restantes electores x } 0,01 \text { U.F }\end{array}$ \\
\hline Presidente de la República & - & $\begin{array}{l}1^{\text {ra }} \text { Vuelta: } 0,03 \times \mathrm{n}^{\mathrm{o}} \text { electores } \\
2^{\mathrm{da}} \text { Vuelta: } 0,01 \times \mathrm{n}^{\circ} \text { electores }\end{array}$ \\
\hline
\end{tabular}

del sistema democrático. Si se tiene en cuenta que la justificada preocupación que surge de la generalizada percepción de los partidos políticos como organizaciones poco confiables $^{25}$ y corruptas $^{26}$, la búsqueda de antídotos para esta situación tienen directa relación con garantizar un conveniente marco normativo que limite la injerencia del dinero en la política, evitando la principal fuente de corrupción del sistema político. Sabido es que en muchas ocasiones es más rentable para quienes poseen poder económico "invertir" en financiamiento político en la medida que ello le garantiza la captura de la autoridad y la consiguiente obtención de futuras ventajas generadas desde el propio Estado ${ }^{27}$.

${ }^{24}$ Para las elecciones presidenciales de 2013 el límite de gasto electoral por candidato y tipo de elección se efectuó por el Director del Servicio Electoral mediante Resolución "O" N ${ }^{\circ} 10.157$, de fecha 10 de mayo de 2013, según el valor de la unidad de fomento al día 23 de mayo de 2013 (\$22.915,58; equivalentes a 41 USD) a base de la cantidad de electores del respectivo territorio.

${ }^{25}$ Recordemos que el Barómetro de la Política Chilena del Centro de Estudios de la Realidad Contemporánea, de enero de 2014, reportaba que apenas el $10 \%$ de las personas confía en los partidos políticos.

${ }^{26}$ De acuerdo con Barómetro Global de la Corrupción realizado por Transparencia Internacional, realizado en 2013, en 51 países de los 107 incluidos en el estudio, los partidos políticos son considerados como la institución más corrupta, Chile es uno de ellos. De un puntaje máximo de 5 equivalente a extremadamente corrupto la clasificación que los partidos políticos obtuvieron fue muy cercana a este, esto es 4,2, cifra que además está por encima del promedio general del estudio, consistente en 3,8. Vid. Transparency International Chile, "Impacto de la Corrupción en Diferentes Sectores e Instituciones (todos los países)". Disponible en: http://www. chiletransparente.cl/wp-content/uploads/2013/07/Barómetro-2013-v-1-0.pdf [consulta: 2 de junio de 2014].

${ }^{27}$ Como arista del caso SQM, en el ámbito pesquero se destapó un caso de fraude tributario combinado con financiamiento ilegal de la política. Según CIPER, los receptores de dinero mediante boletas emitidas a Corpesca, Pesquera El Golfo y la Asociación de Industriales Pesqueros, eran del entorno del ex-Ministro de Economía P. Longueira, quien negoció la Ley de Pesca que favoreció ampliamente a la industria. Además de ello, las grandes empresas pesqueras -apunta el Reportaje- han tenido un rol relevante en los aportes legales a campañas políticas por medio del SERVEL. Vid. Jara, M. y Ramírez, P., Financiamiento ilegal de la política: Los 
La Ley 19.884 reconoce dos tipos de financiamiento: el financiamiento privado y el financiamiento público.

\section{Financiamiento privado y problemas de transparencia}

De acuerdo con el artículo $8^{\circ}$ de la Ley 19.884 se entiende por este toda contribución en dinero, o estimable en dinero, que se efectúe a un candidato o partido político, sea que se materialice bajo la forma de mutuo, donación, comodato o cualquier acto o contrato a título gratuito, destinado al financiamiento de gastos electorales.

El Donante es la persona natural o jurídica que hace una contribución en dinero, o estimable en dinero, que se encuentra destinada al financiamiento de gastos electorales.

El Donatario es la persona que recibe y acepta la donación, puede ser un candidato o un partido político.

Los límites totales por donante privado para cada tipo de elección son los siguientes de acuerdo a lo estipulado por el artículo 9 de la Ley 19.884:

\section{LÍMITES TOTALES POR TIPO DE ELECCIÓN Y DONANTE}

\begin{tabular}{lcc}
\hline Tipo de elección/donante & Límite en U.F. & $\begin{array}{c}\text { Monto equivalente en pesos } \\
\text { para elecciones de } 2013^{28}\end{array}$ \\
\hline Senador & 1.250 & $\$ 28.644 .475$ \\
\hline Diputado & 1.250 & $\$ 28.644 .475$ \\
\hline Alcalde $^{29}$ & 1.000 & - \\
\hline Concejal $^{30}$ & 1.000 & - \\
\hline Consejero Regional (circunscripción provincial) $^{\text {Presidente de la República }}$ & 1.000 & $\$ 22.915 .580$ \\
\hline $\begin{array}{l}\text { Aportes a distintos candidatos por una sola persona en } \\
\text { una misma elección }\end{array}$ & 10.000 & $\$ 45.831 .160$ \\
\hline $\begin{array}{l}\text { Aportes a un partido político por una sola persona en } \\
\text { una misma elección }\end{array}$ & 10.000 & $\$ 2.000 .906$ \\
\hline
\end{tabular}

pagos de las pesqueras, Reportaje de Investigación, Ciper, 22 de abril de 2015. Disponible en: http://ciperchile. cl/2015/04/22/financiamiento-ilegal-de-la-politica-los-pagos-de-las-pesqueras/ [consulta: 20 de agosto de 2015 ].

${ }^{28}$ Para las elecciones presidenciales de 2013 el límite de gasto electoral por candidato y tipo de elección se efectuó por el Director del Servicio Electoral mediante Resolución "O" No 10157, de fecha 10 de mayo de 2013, según el valor de la unidad de fomento al día 23 de mayo de $2013(\$ 22.915,58)$ a base de la cantidad de electores del respectivo territorio.

${ }^{29}$ En 2013 no se realizaron elecciones municipales.

${ }^{30}$ Ídem. 
El financiamiento privado se materializa mediante aportes o donaciones, los que se clasifican de la siguiente manera: aportes propios, aportes anónimos, aportes reservados y aportes privados de carácter público. Cada uno de ellos debe cumplir con requisitos específicos. Para las definiciones que se precisan a continuación nos apoyamos en el manual de consulta realizado por el Servicio Electoral para las últimas elecciones ${ }^{31}$.

Los aportes propios están definidos en el artículo $9^{\circ}$ inc. 3 de la Ley 19.884, comprendiéndose entre tales las contribuciones realizadas con cargo al propio patrimonio de los candidatos, como sueldos, asignaciones u honorarios que perciban en el ejercicio de cualquier actividad lícita, pensiones, créditos obtenidos, retiros de capital o de intereses de fondos mutuos o depósitos a plazo, etc. Su única restricción es que no sobrepasen lo establecido como límite de gasto electoral.

Los problemas de transparencia del gasto electoral se suscitan en especial en relación con los aportes calificados como anónimos y reservados según se examina a continuación. El sistema ha favorecido el secretismo de los aportantes, por lo que no debe llamar la atención que el $90 \%$ de los aportes privados de las campañas políticas tengan el carácter bien de anónimos o reservados procedentes fundamentalmente de empresas ${ }^{32}$ pertenecientes o vinculadas a los grupos económicos más importantes, que además tienen la práctica de solicitar beneficios tributarios ${ }^{33}$.

Los aportes anónimos según el artículo $17^{\circ}$ de la Ley 19.884 son todos los aportes privados en dinero cuyo importe o monto no supere el equivalente en pesos a veinte unidades de fomento, tope máximo que para las elecciones de 2013 equivalía a montos iguales o inferiores a $\$ 458.311$.

Pero además, durante el período de campaña electoral, ningún candidato o partido político podrá recibir por este concepto más del $20 \%$ del límite del gasto electoral definido.

${ }^{31}$ SERVEL, Manual de Gasto Electoral. Elecciones Presidencial, Parlamentarias y Consejeros Regionales 2013, Santiago, 2013, pp. 9-10. Disponible en: http://www.24horas.cl/politica/decisionfinal/article904537. ece/BINARY/Manual+Gasto+Electoral+2013 [consulta: 2 de junio de 2014].

32 En las elecciones de 2013, los aportes reservados procedieron de 297 empresas y 12 particulares. Los aportes anónimos y reservados sumaban el $90 \%$ de los fondos privados recibidos por los candidatos. Llama aún más la atención que las donaciones privadas de un grupo de parlamentarios sea $100 \%$ recibido con carácter de reservados. Vid. Partarrieu, B., El $90 \%$ de los aportes privados a las campañas políticas es secreto, Reportaje de Investigación, Ciper, 8 de octubre de 2014. Disponible en: http://ciperchile.cl/2014/10/08/ el-90-de-los-aportes-privados-a-las-campanas-politicas-es-secreto/ [consulta 10/08/2015].

33 Un dato interesante es que de las 40 empresas más transadas de la Bolsa, que componen el Índice IPSA, 19 de ellas -directamente o mediante sus filiales- realizaron aportes en la última elección. También llama la atención que 242 empresas habrían postulado a beneficios tributarios por aportes a la actividad política durante el 2013, año de las últimas elecciones parlamentarias y presidenciales. En la Declaración Anual del Impuesto a la Renta de 2014 se declararon en "Gastos por Donaciones para fines políticos" (código 793) la suma de \$13.700 millones en 2013. Aún así, la cifra de 242 empresas no concuerda con las 300 personas jurídicas que registraron en el SERVEL sus aportes reservados durante ese mismo año. La diferencia tal vez se puede explicar porque algunas no hicieron uso de las franquicias tributarias. Vid. La Tercera, Empresas que financian la politica, noticia del 19 de octubre de 2014. Disponible en: http://www.latercera.com/noticia/ politica/2014/10/674-600874-9-empresas-que-financian-la-politica.shtml [consulta 12 de agosto de 2015] y Matamala, D., La Lista completa: la verdad sobre las 1.123 empresas que financian la política en Chile, Reportaje de Investigación, Ciper, 23 de abril de 2015. Disponible en: http://ciperchile.cl/2015/04/23/la-lista-completala-verdad-sobre-las-1-123-empresas-que-financian-la-politica-en-chile/ [consulta 12 de agosto de 2015]. 
Respecto de la identidad de quien hizo el aporte, se establece que cualquier aportante podrá solicitar se consigne su identidad y el monto de su contribución, de tal modo que únicamente pueden ser conocidos por el donante y la candidatura donataria la que lo recibe directamente y debe registrarlo. Así, en la cuenta de ingresos electorales este aporte puede registrarse de dos formas: presentar el registro por el monto total, indicando claramente el número de aportes a los que corresponde; o bien presentar el registro uno a uno.

Los aportes reservados según el artículo $18^{\circ}$ de la Ley 19.884 son los aportes privados en dinero superiores a veinte unidades de fomento $(\$ 458.311,6$ para las elecciones de 2013) e inferiores al $10 \%$ del límite de gasto electoral del candidato o partido político, los que pueden realizarse dentro del período determinado para la Campaña Electoral. Se realizan mediante la cuenta del SERVEL ${ }^{34}$, quien debe guardar la reserva.

En lo que respecta a estos aportes debe mantenerse absoluta reserva de la identidad del donante y del monto de su contribución, salvo que el aportante solicite que se consigne su identidad y el monto de su contribución o se exceda del límite máximo permitido para este tipo de aportes. Esto último culmina de generar una curiosa situación: tanto los aportes anónimos como los reservados (estos últimos a opción del donante) pueden ser conocidos por las candidaturas pero no por la ciudadanía. De otro lado, se ha de considerar la existencia de montos máximos permitidos para mantener la reserva de la contribución que señala el artículo 18 de la Ley 19.884. En consecuencia, por cada tipo de elección los montos máximos de los aportes que están afectos a reserva se resumen en el siguiente cuadro:

\section{Cuadro 3 \\ APORTES RESERVADOS POR TIPO DE ELECCIÓN Y DONANTE}

\begin{tabular}{lcc}
\hline Tipo de elección/donante & $\begin{array}{c}\text { Monto límite } \\
\text { en U.F. }\end{array}$ & $\begin{array}{c}\text { Monto límite en pesos } \\
\text { para la elección de } 2013^{35}\end{array}$ \\
\hline Senador & 800 & $\$ 18.332 .464$ \\
\hline Diputado & 800 & $\$ 18.332 .464$ \\
\hline Alcalde $^{36}$ & 600 & - \\
\hline Concejal $^{37}$ & 600 & - \\
\hline Consejero Regional (circunscripción provincial) $^{3}$ & 600 & $\$ 13.749 .348$ \\
\hline Presidente de la República & $1^{\text {ra }}$ Vuelta: 1.500 & $\$ 34.373 .370$ \\
\hline Aporte de una persona a distintos candidatos & 3.000 & $\$ 68.746 .740$ \\
\hline Aporte de una persona a un partido político & 3.000 & $\$ 68.746 .740$ \\
\hline
\end{tabular}

34 El SERVEL emitirá un certificado en cada caso consignando el monto de la donación, debiendo transferirla semanalmente a la cuenta indicada por el Administrador Electoral correspondiente.

${ }^{35}$ Para las elecciones presidenciales de 2013 el límite de gasto electoral por candidato y tipo de elección se efectuó por el Director del Servicio Electoral mediante Resolución "O" No 10157, de fecha 10 de mayo de 2013, según el valor de la unidad de fomento al día 23 de mayo de $2013(\$ 22.915,58)$ en base a la cantidad de electores del respectivo territorio.

${ }^{36}$ En 2013 no se realizaron elecciones municipales.

37 Ídem. 
Sin duda, este tipo de aporte presenta una gran problemática por la opción del legislador de permitir que las aportaciones superiores a 20 UF y hasta los respectivos límites señalados tengan el carácter de reservados impidiendo sobre todo el control social que exige poder saber quién donó, cuánto y a quién ${ }^{38}$. Si bien en el ámbito especializado se discute acerca de la conveniencia o no de establecer límites a los aportes privados, al igual que hay dudas respecto de la efectividad del establecimiento de financiamiento público para las campañas electorales, es más aceptado que uno de los mecanismos más efectivos de control del efecto perverso del dinero en la política es la transparencia del gasto electoral, lo que se constata como tendencia en la experiencia comparada (USA, Italia, Japón y Canadá) ${ }^{39}$, calificándose incluso de una situación antediluviana el que los actores principales, candidatos o partidos políticos, estén exentos de la obligación de mantener registros de sus ingresos y gastos, y de entregar informes de ellos a las autoridades para su divulgación al público. Al parecer esta tendencia es la que ha triunfado en el actual gobierno de la presidenta Bachelet y se ha materializado en un proyecto de ley enviado recientemente al Congreso ${ }^{40}$. Ciertamente, en esta materia también hay detractores que se fundan en los costos que esto supone y la

${ }^{38}$ Monje Reyes, P., La Ley de Financiamiento de Gasto Electoral. Un Análisis Crítico desde la Gestión Pública, en Agenda Pública, Año IV-No 6, 2005, pp. 25-32. Disponible en: http://www.agendapublica.uchile.cl/n6/ monje.pdf [consulta: 11 de junio de 2014].

39 Rosales apunta que en el caso norteamericano la ley obliga a que los candidatos y representantes elegidos deben entregar un reporte financiero de sus gastos cuando están en competencia por un cargo de elección popular. Estos informes son totalmente públicos, por lo que están a disposición de cualquier interesado. Se les puede consultar y recibir copia certificada, previa solicitud escrita con nombre y domicilio del solicitante, a condición de que declare estar informado de la reglamentación relativa a la obtención y uso de los mismos. En Rosales, C.M., El Control Jurisdiccional del Gasto Electoral en los Estados Unidos de América, en González Oropeza, M. y Cienfuegos Salgado, D. (coordinadores), Cuestiones y Reflexiones PolíticoElectorales, Ed. H. Congreso del Estado de Guerrero, Congreso del Estado de Coahuila, Poder Judicial del Estado de Durango y Universidad Autónoma de Guerrero, México, 2011, pp. 415-427. Disponible en: http://biblio.juridicas.unam.mx/libros/7/3031/23.pdf [consulta: 11 de junio de 2014]. Según Mann, en el caso italiano, desde 1974, año en que se aprobaron varias regulaciones al financiamiento político, se incluyó entre otras cosas la publicidad obligatoria acerca de quién donó, cuándo y a quién. De forma similar, en Japón las reformas en la normativa de financiamiento electoral incluyeron la reducción del umbral a partir del cual deben ser publicitadas las donaciones de empresas individuales. Con ello, las compañías se vieron expuestas a que se sepa cuánto le han dado y a quién, lo que al originarles problemas con sus accionistas y con otros políticos funciona como mecanismo disuasorio. Canadá -subraya Mann- se constituye en uno de los sistemas más regulados dentro del mundo democrático; entre otras, comprende un mecanismo estricto de publicidad obligatoria de los aportes individuales, siendo catalogado como un ejemplo, donde se ha hecho razonablemente bien y en donde existe un alto grado de satisfacción de los canadienses con su regulación del financiamiento político. En Mann, Th., "Dilemas de las Regulaciones del Financiamiento Político”, en Valdés Prieto, S. (editor), Reforma del Estado, Volumen I., Centro de Estudios Públicos, Santiago de Chile, 2000, pp. 2-22. Disponible en: http://www.cepchile.cl/dms/archivo_3512_1742/refor1_01_mann.pdf [consulta: 11 de junio de 2014].

${ }^{40}$ El 15 de diciembre de 2014 se anunció la firma del proyecto de ley "Fortalecimiento y Transparencia de la Democracia", que entre otras contempla la eliminación de los aportes reservados y anónimos por parte de empresas o personas jurídicas. Ello es visto por parte de la Presidenta de la República, señora Michelle Bachelet, como la expresión de lo que como sociedad compartimos sobre lo que debe ser la política en una sociedad democrática. Más aún, subrayó la mandataria que la eliminación de los aportes de las personas jurídicas se justifica en que las empresas no votan y no tienen por qué financiar campañas. Vid. Emol-Chile (15 diciembre 2014). 
consiguiente barrera de entrada que ello puede generar para nuevos competidores políticos que no cuentan con el apoyo electoral para justificar los costos fijos requeridos para cumplir con las leyes de transparencia ${ }^{41}$. Desde otra perspectiva, la asimetría de información entre los donatarios y la ciudadanía es cuestionada para el caso de Chile, argumentándose que ello puede aumentar el riesgo de corrupción pues facilita la extorsión de los candidatos poderosos contra los adherentes que quisieran donar a los candidatos rivales. Así, se recomendó que se revele poca información de detalle sobre "quién donó y cuánto" ${ }^{2}$. De más está decir que el sistema de financiamiento chileno establecido en el artículo $18^{\circ}$ de la Ley 19.884 incorporó esta propuesta estableciendo un sistema de confidencialidad que protege la privacidad de los donantes, creándose en el SERVEL un sistema electrónico que asegura tanto la reserva de la identidad del donante como también garantiza que este no obtendrá documento alguno que permita identificar su donación ante el donatario o terceros (artículo 19 de la Ley 19.884) ${ }^{43}$.

Los aportes privados de carácter público son aquellos que se efectúan en dinero que no tengan el carácter de anónimos o reservados, así como las donaciones de bienes y servicios que deberán ser estimadas en dinero. El artículo 20 de la Ley 19.884 exige que para determinar si las donaciones deben ser públicas se deberán sumar todas las donaciones hechas por el mismo donante, al mismo candidato o partido o conjunto de candidatos de un mismo partido, en la misma elección. Por la exigencia de publicidad estos aportes deben constar por escrito e indicarse la identidad del aportante y deberá consignarse por medio de boleta, factura, comprobante de depósito en cuenta bancaria, recibo de dinero o especies, etcétera.

Finalmente, a lo ya señalado hay que añadir otras formas de financiamiento privado que se obtienen mediante créditos con instituciones financieras adquiridos por los candidatos o partidos; aportes por trabajo voluntario; y usufructo de bienes.

\section{El financiamiento público}

Es el otorgado por el Estado como anticipo o reembolso de gastos en que hubieren incurrido los candidatos y los partidos, en las cantidades, proporciones y formas que establecen los artículos $13^{\circ}$ y siguientes de la Ley 19.884 , contenidos en el párrafo $2^{\circ}$ del Título II sobre Financiamiento de las Campañas.

${ }^{41}$ Palda, F., "Regulación del Financiamiento Electoral en Chile: Lecciones de Canadá y los Estados Unidos", en Valdés Prieto, S. (editor), Reforma del Estado, Volumen I., Centro de Estudios Públicos, Santiago, 2000, p. 268. Disponible en: http://www.cepchile.cl/dms/archivo_3517_1747/refor1_06_palda.pdf [consulta: 11 de junio de 2014$].$

${ }^{42}$ Contardo Díaz-Muñoz, F., "Donaciones Políticas Confidenciales", en Valdés Prieto, S. (editor) Reforma del Estado, Volumen I, Centro de Estudios Públicos, Santiago de Chile, 2000, pp. 362-382. Disponible en: http://www.cepchile.cl/dms/archivo_3520_1750/refor1_09_contardo.pdf [consulta: 11 de junio de 2014 ].

43 El citado artículo 19 de la Ley 19.884 establece un procedimiento para realizar las donaciones que tienen carácter de reservadas. Estas se realizarán directamente en una cuenta única que mantiene el SERVEL y el donante solo podrá obtener un certificado del monto aportado. La contribución realizada por el donante la puede distribuir entre distintos candidatos o partidos debiendo atender a las restricciones legales señaladas. 
Excepcionalmente, para las elecciones parlamentarias de 2017, 2021, 2025 y 2029 los partidos políticos a los que pertenezcan las mujeres candidatas a diputadas o senadoras que consigan ser proclamadas electas, tendrán derecho a un reembolso de 500 UF por cada una de ellas. Dicho monto puede ser empleado por los partidos beneficiarios para desarrollar programas y actividades de fomento a la inclusión y participación de las mujeres en política (artículo segundo transitorio de la Ley 19.884 introducido por el $\mathrm{n}^{\circ} 2$ del artículo $2^{\circ}$ de la Ley 20.840). De igual modo, la ley reconoce que para las elecciones parlamentarias señaladas en el párrafo precedente las candidatas a senadoras y diputadas tienen derecho a un reembolso adicional de sus gastos electorales, de cargo fiscal, de 0,0100 UF por cada voto obtenido (artículo segundo transitorio de la Ley 19.884 introducido por el $\mathrm{N}^{\circ} 3$ del artículo $2^{\circ}$ de la Ley 20.840).

El Fisco financiará los gastos de campaña electoral otorgando un anticipo al inicio de la campaña a cada partido inscrito que presente candidatos a la respectiva elección de senadores, diputados, alcaldes, consejeros regionales o concejales, en función de una fracción de UF y los votos obtenidos en anterior elección conforme se resume en el siguiente cuadro:

\section{Cuadro 4 \\ FINANCIAMIENTO PÚBLICO}

\begin{tabular}{|c|c|c|}
\hline Tipo de elección & Partido político / Donatario & $\begin{array}{l}\text { Monto del anticipo } \\
\text { (artículo } 14, \text { Ley 19.884) }\end{array}$ \\
\hline $\begin{array}{l}\text { Senador, diputado, alcaldes, } \\
\text { consejeros regionales o concejales }\end{array}$ & $\begin{array}{l}\text { Participó en última elección } \\
\text { de igual naturaleza }\end{array}$ & $\begin{array}{l}\mathrm{n}^{\mathrm{o}} \text { sufragios x } 0,01 \mathrm{UF}^{42} \\
\text { (referenciados al número de votos obtenidos } \\
\text { en última elección de similar naturaleza) }\end{array}$ \\
\hline $\begin{array}{l}\text { Senador, diputado, alcaldes, } \\
\text { consejeros regionales o concejales }\end{array}$ & $\begin{array}{l}\text { No participó en última elec- } \\
\text { ción de igual naturaleza }\end{array}$ & $\begin{array}{l}\text { Equivalente a cantidad igual a la que co- } \\
\text { rresponde al partido político que hubiere } \\
\text { obtenido en última elección el menor } \\
\text { número de sufragios. }\end{array}$ \\
\hline $\begin{array}{l}\text { Senador, diputado, alcaldes, } \\
\text { consejeros regionales o concejales }\end{array}$ & Candidatos independientes & $\begin{array}{l}\text { Se prorrateará entre todos un monto si- } \\
\text { milar al que le corresponda al partido que } \\
\text { hubiere obtenido en última elección de } \\
\text { igual naturaleza el menor número de votos. }\end{array}$ \\
\hline Fecha de pago anticipo: & \multicolumn{2}{|c|}{5 días siguientes a la inscripción de las candidaturas } \\
\hline
\end{tabular}

Por su parte, el Fisco reembolsará a los candidatos y a los candidatos independientes que no estuvieren incluidos en un pacto o subpacto y a los partidos políticos, los gastos electorales en que hubieren incurrido durante la campaña electoral en función de una fracción de UF y los votos obtenidos en la respectiva elección, sujeto a las siguientes limitaciones:

\footnotetext{
${ }^{44}$ En las elecciones de 2013 el 0,01 UF significaba 229 pesos chilenos por voto o aproximadamente 0,4 USD.
} 


\section{Cuadro 5 \\ FINANCIAMIENTO PÚBLICO}

\begin{tabular}{lll}
\hline \multicolumn{1}{c}{ Tipo de elección } & Partido político/Donatario & $\begin{array}{c}\text { Monto límite del reembolso } \\
\text { (artículo 15, Ley 19.884) }\end{array}$ \\
\hline Presidente de la República & Candidatos y partidos políticos & $\begin{array}{l}1^{\text {ra }} \text { Vuelta: }{ }^{\circ} \text { sufragios x 0,03 U.F } \\
2^{\text {da }}\end{array}$ \\
\hline $\begin{array}{l}\text { Senadolta: } n^{\circ} \text { sufragios x 0,01 U.F. } \\
\text { Consejeros regionales o con- } \\
\text { cejales }\end{array}$ & $\begin{array}{l}\text { Candidatos, candidatos indepen- } \\
\text { dientes no incluidos en un pacto } \\
\text { o subpactos y a partidos políticos }\end{array}$ & 0,03 U.F. x n notos obtenidos \\
\hline Plazo para autorizar el reembolso: & $\begin{array}{l}\text { Dentro de los 20 días siguientes a la resolución del Director del SERVEL } \\
\text { que aprueba la cuenta de ingresos y gastos }\end{array}$ \\
\hline
\end{tabular}

Es claro que el reembolso solo procede dentro de los límites legales señalados siempre que los gastos no hayan sido financiados por otro tipo de aportes no reembolsables por los candidatos o partidos, eso sí una vez que esté aprobada la cuenta, lo que deberá ser acreditado. A su vez, la ley faculta a los candidatos para ceder a sus partidos su derecho al reembolso cuando estos hubieren asumido el pago correspondiente a los proveedores por bienes y servicios prestados en la campaña electoral. Igualmente, los candidatos y partidos políticos también pueden otorgar mandato a las instituciones financieras con las que hubieren contratado créditos a fin que el SERVEL autorice el pago de los créditos con el reembolso que se determine.

Se ha de destacar que es primera vez en la historia en que el Estado asume la responsabilidad de proveer financiamiento público a las contiendas electorales, pero ciertamente hay que tener claro que el financiamiento por sí solo no produce una democratización del sistema político, todo depende de cómo se asigne el dinero y los incentivos que se provee para su correcta aplicación. Lo señalado nos lleva necesariamente a examinar cómo funciona el sistema de control del gasto electoral, elemento que se torna crucial para asegurar la coherencia entre la idea de generar un sistema político más inclusivo que efectivamente promueva una mayor participación política e involucramiento de los ciudadanos.

\section{El CONTROL DEL GASTO ELECTORAL}

La crisis política que se ha desencadenado ligada a los escándalos de financiamiento ilegal y de corrupción conocidos como los llamados casos "Penta" y "SQM" han revelado las limitaciones existentes para el control de la transparencia y los límites de los gastos electorales, en tres aspectos importantes:

${ }^{45}$ En las elecciones de 2013 el 0,03 UF significaba 687 pesos chilenos por voto o aproximadamente 1,2 USD. 
a) Existen dudas sobre el origen del problema. De un lado los políticos acusan presiones indebidas, y por otra parte representantes del mundo empresarial niegan que sus gremios sean los que persigan la relación con el poder ${ }^{46}$.

b) Los límites de los aportes privados, en el caso de las empresas, están asociados a la personalidad jurídica propia prescindiendo del criterio del controlador económico.

c) Los límites de los aportes máximo por empresa (de 10 mil UF) están establecidos por tipo de elección, por lo que el año en que coinciden elecciones presidenciales, senadores, diputados y consejeros regionales (como ocurrió en el 2013), los montos involucrados pueden multiplicarse y hacerse llegar por medio de las distintas compañías que integran un grupo económico.

Otra importante problemática que incide limitadoramente sobre el control del gasto electoral está relacionada con la institucionalidad encargada de la administración electoral. El Servicio Electoral ${ }^{47}$ es el organismo responsable del control de la normativa relacionada con el financiamiento del gasto electoral contenidas en la Ley 19.884. Su naturaleza jurídica se define por ser un órgano descentralizado que integra la Administración del Estado, que por consiguiente se relaciona con el Presidente de la República mediante el Ministerio del Interior (artículo 57 de la Ley 18.556). La singularidad que tiene este

46 “Aquí dicen que las empresas están preocupadas de darles plata a los políticos. Esto es todo al revés: es el desfile de los políticos a las empresas para que les pongan las lucas. Esa es la verdad y todos ustedes lo tienen claro, porque capaz que algunos de ustedes estuvieron en el desfile”, afirmó Andrés Santa Cruz, presidente de la CPC. Vid. TVN 24 Horas, Presidente de la CPC en Estado Nacional: "Hay que diferenciar las actitudes del empresariado", en programa Estado Nacional del 28 de septiembre de 2014. Disponible en: http://www.24horas.cl/programas/estadonacional/presidente-de-la-cpc-en-estado-nacional-hay-quediferenciar-las-actitudes-del-empresariado-1430878 [consulta: 10/08/2015].

${ }^{47}$ Una breve cronología del SERVEL se recapitula a través de los siguientes datos:

El 17 de marzo de 1925, nació el Servicio Electoral de Chile, como Conservador del Registro Electoral, gracias al Artículo 23 del Decreto Ley 343, publicado en el Diario Oficial.

En octubre de 1925, mediante el Decreto Ley 623, se determinó que la Institución estuviese integrada por seis funcionarios, para atender a los 302.142 electores existentes en esa época en el país.

En mayo de 1931, mediante el Decreto con Fuerza de Ley 82, la Institución pasó a llamarse Dirección del Registro Electoral.

Entre 1973 y 1986, el Servicio Electoral permaneció cerrado y los funcionarios a esa fecha existentes fueron destinados a otras reparticiones públicas; gran parte de los archivos históricos y toda la información del Registro Electoral y partidos políticos a esa fecha se destruyó, por lo cual, hoy no existen datos sobre los procesos electorales anteriores a esos años.

El Aniversario de la Institución se celebra el 1 de octubre, dado que en esa fecha en 1986, entró en vigencia la Ley 18.556 "Orgánica Constitucional sobre Sistema de Inscripciones Electorales y Servicio Electoral”, que nombró a la Institución como Servicio Electoral de Chile.

El 18 de febrero de 2013, asumió el Consejo Directivo del Servicio Electoral, creado por el Artículo 57 de Ley 20.568, publicada el 31 de enero de 2012.

La Ley 20.568, que Regula la inscripción automática, modifica el Servicio Electoral y moderniza el sistema de votaciones, publicada en Diario Oficial de 31 de enero de 2012, creó el Consejo Directivo del Servicio Electoral, el cual está compuesto por cinco consejeros designados por el Presidente de la República, previo acuerdo del Senado adoptado por los tres quintos de sus miembros en ejercicio. Vid. http://www. servel.cl/ss/site/servel.html [consulta: 31 mayo de 2014]. 
servicio es que las máximas autoridades del mismo, esto es tanto su Director como el Subdirector, no son cargos de exclusiva confianza del Presidente de la República. Dichas autoridades son nombradas por el Consejo Directivo del propio SERVEL ${ }^{48}$-creado en 2012 por la Ley 20.568- a partir de una quina propuesta para el cargo por el Consejo de la Alta Dirección Pública, proceso de selección que ser ajustará a las normas contenidas en el Título VI de la Ley 19.882. Esta circunstancia permite afirmar que el SERVEL cuenta con una autonomía más efectiva respecto de la autoridad presidencial, situación bastante inusual en nuestro medio, pero que es del todo necesaria para evitar injerencias indebidas del poder político.

Sin embargo, junto a lo señalado es también sustancial proveer de garantías económicas que le aseguren el financiamiento adecuado con independencia del poder político, a fin de que este servicio pueda contar, por ejemplo, con herramientas tecnológicas que le ayuden a potenciar en línea su importante función fiscalizadora del gasto electoral, mejorando la oportunidad en que se hace el control. Otro importante aspecto es la necesidad de incrementar la dotación del servicio con personal suficiente y adecuadamente capacitado para ejercer la labor de fiscalización que demandan las prohibiciones y obligaciones contenidas en la Ley $19.884^{49}$ superando la situación actual en la que básicamente hace un control formal por medio de accesos contables sin que alcance a revisar si las boletas que se presentan corresponden a servicios realmente contratados.

En materia de gasto electoral las funciones principales del SERVEL son ejercidas por el Director del Servicio quien tiene la representación legal del mismo, siendo quien legalmente ejerce la jefatura superior de aquel (artículo 68 de la Ley 18.556). A estos efectos, las funciones establecidas en la Ley 19.884 que el SERVEL debe cumplir son:

i) Recibir de los Administradores Electorales la información contable y la documentación relativa a ingresos y gastos electorales.

ii) Revisar las cuentas de ingresos y gastos electorales presentados.

iii) Aprobar o rechazar las cuentas presentadas por los Administradores Electorales y publicarlas.

iv) Transferir los recursos públicos o recibir los remanentes de los Administradores Electorales.

\footnotetext{
48 Ver artículo 67 letra h) de la Ley 18.556.

${ }^{49}$ Una de las debilidades institucionales del SERVEL es su escasa dotación de personal. De acuerdo con la entonces Ministra Secretaria General de la Presidencia, Ximena Rincón, este servicio cuenta con 280 funcionarios, de ellos solo $15 \%$ es profesional. Para cada elección se contratan contadores auditores para revisar los gastos de campaña, en 2013 fueron 70 los contratados, en El Dínamo, Servel será reestructurado en proyecto para transparentar el financiamiento de la política, noticia del 6 de noviembre de 2014. Disponible en: http://www.eldinamo.cl/pais/2014/11/06/servel-proyecto-financimiento-politica/ [consulta: 12/08/2015]. En el personal de planta de julio de 2015 además del Jefe de la Unidad de Control de Gasto Electoral solo hay otro profesional vinculado a esta Unidad, a los que se debe sumar otro profesional en calidad de a contrata. Este dato fue obtenido del banner Gobierno Transparente en el sitio electrónico del SERVEL.
} 
v) Definir si las denuncias presentadas ameritan la formulación de cargos o su archivo por falta de méritos.

vi) Iniciar, de oficio o por denuncia presentada, los procedimientos administrativos a que da lugar la Ley 19.884.

vii) Aplicar multas por infracciones a la Ley 19.884.

El control que realiza el SERVEL es uno de naturaleza institucional avocada al seguimiento y observación de los procesos electorales. La ley regula la materia que debe controlar la oportunidad en que debe ejercer dicho control y los efectos del mismo (los que incluso pueden derivar en sanciones administrativas). Ahora bien, el sistema de control que la ley diseña no radica en la iniciativa del servicio sino que se basa en la información que le proveen los candidatos y partidos políticos. Un aspecto fundamental es que el cumplimiento de las obligaciones del SERVEL garantiza y hace posible el acceso a la información sobre financiamiento electoral que es de relevancia pública, por lo que es crucial reforzar su capacidad para fiscalizar los gastos en detalle y sus justificaciones, tanto como los movimientos bancarios (ingresos y egresos), exceptuándolo de la reserva bancaria, tarea en la que se puede asistir de las nuevas tecnologías ${ }^{50}$.

Del modo como la Ley 19.884 regula la transparencia, los límites y el control del gasto electoral se debe concluir que esta no potenció el control social, que puede resultar un eficaz colaborador. Muy por el contrario, básicamente la única herramienta potente que la citada ley contempla se reduce al acceso a la información de las cuentas de ingresos y gastos que los candidatos y administradores electorales deben presentar ante el SERVEL. De conformidad con el artículo 48 de la Ley 19.884 las cuentas de ingresos y gastos electorales presentadas ante el Director del Servicio Electoral son públicas, por lo que cualquier ciudadano interesado puede tener acceso a ellas (obteniendo copia de ellas a su costa). Complementariamente, la ley establece que es obligación del Director del SERVEL publicar en Internet las cuentas de las candidaturas a Presidente de la República, senador y diputado, así como de los partidos políticos dentro de los 15 días de presentación de la respectiva cuenta, debiendo actualizar la información e indicar si tales cuentas han sido aceptadas, rechazadas u observadas. Es posible observar que la plataforma en la que se exhibe esta información es poco amigable con los usuarios, lo que dificulta la auscultación ciudadana.

Como se ha señalado el control social se encuentra muy limitado por las opciones que el legislador ha efectuado vinculadas a quiénes están facultados para denunciar las infracciones a la Ley 19.884; peor aún, los efectos negativos de esta opción legislativa han sido potenciados por la interpretación estricta que el SERVEL ha dado a estas limitaciones. Así, respecto de quiénes tienen la posibilidad de denunciar hechos constitutivos de infracciones al límite de gastos electorales establecidos en la Ley 19.884, el artículo $6^{\circ}$ de la ley solo reconoce esta atribución a los partidos políticos (por medio

${ }^{50}$ De la Calle Lombana, H., "La Financiación Ilícita de la Política”, en Hernández Becerra, A. et al., (editores), Derecho Electoral de Latinoamérica. Memorias del II Congreso Iberoamericano de Derecho Electoral, Bogotá, 2013, p. 235. 
de sus representantes) y a los candidatos independientes que hayan participado en la respectiva elección. Resulta decepcionante que el SERVEL niegue la legitimación y desestime por "falta de personería" las denuncias ciudadanas que le representan las infracciones a los límites del gasto electoral incurridas por las distintas candidaturas ${ }^{51}$. En definitiva, la combinación de la prescripción normativa contenida en el artículo $6^{\circ}$ citado y la interpretación que de ella hace el SERVEL restan toda legitimidad para solicitar - vía denuncia- la iniciación de un procedimiento administrativo sancionador por infracciones a los límites del gasto electoral dispuestos por la Ley 19.884 .

El SERVEL está responsabilizado del examen de la veracidad y corrección de las cuentas electorales no así de los medios publicitarios legítimos empleados en la campaña electoral, los cuales son de cargo de Carabineros de Chile y de las municipalidades. Se trata entonces fundamentalmente de un control técnico contable sobre los ingresos y egresos presentados ante el Director del Servicio por los candidatos o administradores electorales para cada uno de los candidatos y partidos políticos.

Si bien la Ley 19.884 da pautas de la forma cómo se debe llevar la contabilidad de los ingresos y gastos electorales, lo que resulta positivo, una debilidad del sistema establecido es el breve plazo que la ley, en su artículo 42, otorga al Director del SERVEL para poder examinar las cuentas y pronunciarse sobre ellas (30 días, prorrogables por una sola vez en 15 días $^{52}$ ). Al cabo, si el Director no se hubiere pronunciado respecto de la cuenta, la ley le otorga el beneficio al cuentadante de entender por aprobada la misma. La debilidad en el sistema de fiscalización señalado se agrava, pues como ya ha advertido Monje $e^{53}$ el SERVEL debe cumplir estas funciones de fiscalización de gran envergadura sin que el legislador, al mismo tiempo, haya atendido a la necesidad de dotarlo de mejores medios tanto tecnológicos como de personal, siendo previsible que ocurra una excesiva recarga de trabajo sobre el personal, arriesgando un mal funcionamiento de las funciones históricas del servicio y un mal cumplimiento de las nuevas. Hasta el momento no se ha desarrollado un sistema de e-control de cuentas que emplee diestramente la tecnología como una aliada en la solución de ese importante problema.

51 Rojas fundamenta esta crítica con lo acontecido en el "caso Labbê" referido al exalcalde de la comuna de Providencia en Santiago quien en 2005 había informado al SERVEL una suma de gasto electoral muy inferior a la que efectivamente había gastado ( $\$ 13$ millones de pesos versus \$62 millones de pesos aproximadamente). En este caso, a pesar que entre los denunciantes se encontraba una excandidata a alcaldesa y presidentes de partidos políticos pero del ámbito comunal (no así algún presidente de partido del nivel nacional), para cursar la denuncia el SERVEL exigía que esta sea ratificada por el presidente de algún partido político. En consecuencia, el SERVEL terminó no dando curso a la denuncia por razones formales invocando una resolución del director ("O” No 2066/2004) que no había sido publicada en el Diario Oficial ni constaba en el sitio web del servicio. Finalmente, el servicio si bien terminó designando en subsidio a un abogado fiscal encargado de investigar los hechos, formalmente no lo hizo a consecuencia de la denuncia recibida, pues esta no fue ratificada por un representante del máximo nivel de un partido. Vid. Rojas, H., Mecanismos de Fiscalización Ciudadana..., op. cit.

52 Tratándose de los actos eleccionarios regulados por la Ley 18.695, el plazo de análisis es un poco mayor, consistente en 60 días.

${ }^{53}$ BCN, La Ley de Financiamiento de Gasto Electoral..., op. cit., p. 30. 
Finalmente, ligado al control del gasto electoral se ha dotado al SERVEL de una de las potestades administrativas más intensas como es la potestad sancionadora que es ejercida por el Director del Servicio, previo procedimiento administrativo sancionador. La Ley 19.884, en su artículo 27-A, introducido por la Ley 19.963, de 2004, haciéndose cargo de una de las críticas de las que fue objeto el texto inicial que estableció un catálogo de sanciones pecuniarias que el SERVEL podría imponer cuando se cometan infracciones a las normas contenidas en los Párrafos $1^{\circ}$ (sobre el financiamiento privado), $2^{\circ}$ (sobre el financiamiento público), $3^{\circ}$ (sobre transparencia del financiamiento) y $4^{\circ}$ (sobre las prohibiciones) todos del Título II Del Financiamiento de las Campañas, eso sí siempre que no tengan asociada una pena específica en la ley. Las sanciones establecidas en el artículo 27-A consisten en multas en beneficio fiscal de acuerdo con la escala que se esquematiza en el siguiente cuadro:

Cuadro 6

SISTEMA DE SANCIONES

Art. 27-A, Ley 19.884

\begin{tabular}{lll}
\hline \multicolumn{1}{c}{ Infracciones a } & Tipo de infractores & \multicolumn{1}{c}{ Multas } \\
\hline Párrafos $1^{\circ}, 3^{\circ}, 4^{\circ}$ del & Candidatos o partidos & - Doble del exceso en la parte que no supere el \\
Título II de la ley & políticos & $30 \%$ \\
& & - Triple del exceso en la parte que supere el \\
& & $30 \%$ y sea inferior al $50 \%$ \\
& - Quíntuple del exceso en la parte que supere \\
& el $50 \%$ (estas multas se expresarán en UF)
\end{tabular}

Párrafo $2^{\circ}$ del Título II Candidatos o partidos de la ley políticos
Triple de las sumas indebidamente recibidas (sin perjuicio de las responsabilidades penales que cupieren a los candidatos o los representantes de los partidos)

Otras disposiciones de la Candidatos o partidos 5 a 50 Unidades Tributarias Mensuales ley sin sanción especial políticos

La Comisión Anticorrupción (2015: 65) ha evaluado que el sistema de control actual del gasto electoral es débil y las sanciones son bajas, además de la inexistencia de capacidad para imponerlas. En mi opinión, siguiendo a De la Calle (2013), el elemento sancionador debe ser enfocado no tanto en el monto de la multa que se puede aplicar, sino más bien en medidas concretas que puedan afectar la posición jurídica del candidato, tales como, en caso de ser electo: la pérdida del escaño; o el no reemplazo del cupo ("silla perdida"), lo que permitiría sancionar al partido que lo propuso; o bien, en el caso de candidatos no electos: inhabilitación para presentarse en otra elección, inhabilitación para recibir financiamiento público, multas, entre otras.

Respecto del procedimiento sancionador, su esquema básico está regulado en el artículo 51 de la Ley 19.884, precepto que fue reglamentado por Resolución del Director del

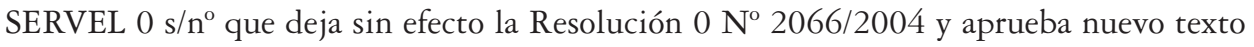


del documento sobre "Conocimiento, Tramitación y Resolución de los Procedimientos Administrativos Sancionatorios iniciados a la luz del artículo 51 de la Ley 19.884 sobre Transparencia, Límite y Control del Gasto Electoral" ${ }^{54}$. El dato que en relación con el procedimiento sancionador interesa destacar es el relativo al plazo que dicho procedimiento puede tomar hasta quedar afinado, el que resulta ser un horizonte temporal muy extenso teniendo en cuenta la relevancia de la oportunidad de la sanción en materia de gasto electoral, esta inobjetablemente es de alto impacto para la salud del sistema democrático. Así, ya que este es un procedimiento administrativo, se le aplica con carácter supletorio la Ley 19.880 de Bases de los Procedimientos Administrativos que establece un plazo general de seis meses aplicable al procedimiento tramitado por el SERVEL, por cuanto la Ley 19.884 no contiene una disposición que regule este aspecto del procedimiento.

Además, la responsabilidad administrativa que correspondiere a funcionarios públicos como consecuencia de infracciones a la Ley 19.884 se hará efectiva directa y exclusivamente por procedimiento disciplinario tramitado por la Contraloría General de la República conforme a las disposiciones de su Ley Orgánica Constitucional. En estos casos, la propuesta de medida disciplinaria de la entidad de control no podrá ser modificada por la autoridad competente para aplicar la sanción, sino mediante resolución fundada sujeta al trámite de toma de razón (artículo 28).

\section{CONCLUSIONES}

Las normas que regulan el financiamiento de las campañas electorales si bien otorgan atribuciones, instrumentos y mecanismos de control al Servicio Electoral, estos resultan inadecuados a las funciones que se le asignan como instancia que debe fiscalizar su cumplimiento.

Lo señalado hace necesario continuar actualizando la regulación del financiamiento electoral, en especial, tanto para adecuarse a los cambios tecnológicos como para contrarrestar mecanismos de evasión y elusión que eventualmente podrían aplicar los regulados. Una medida sencilla como la de limitar a una sola cuenta bancaria en donde se realicen todos los movimientos bancarios de cada candidato (relacionados con aportes y gastos) que, además, el SERVEL pueda consultar en línea (levantando al servicio el secreto bancario) puede ayudar a hacer más eficaz y eficiente su labor.

En otro orden, resulta importante atender a los aspectos relativos al otorgamiento de una adecuada dotación de personal (asegurando un número suficiente, como que estos cuenten con la debida calificación), proveerle de recursos económicos que le permitan

\footnotetext{
${ }^{54}$ Para el presente trabajo se ha consultado la publicación preparada por la Asesoría Jurídica del SERVEL que contiene la citada Resolución que deja sin efecto la Resolución 0 N 2066/2004 del mismo Servicio, sin embargo, se constata que esta carece de número, lo que explica que en los procedimientos sancionadores tramitados por el SERVEL se la identifique por ser la resolución que derogó la Resolución 0 N 2066/2004 que reglamentaba la misma materia. Con ello se verifica la mala técnica jurídica con la que importantes textos normativos han sido sancionados por este Servicio.
} 
alcanzar una mayor modernización y los medios tecnológicos que hagan más eficaz y eficiente la labor de fiscalización, entre otros.

En el caso que se permitan los aportes de personas jurídicas, al menos se deben prohibir o limitar severamente los aportes de contratistas del Estado.

El sistema de transparencia del gasto electoral contemplado en la Ley 19.884 se reduce a la publicidad de las cuentas presentadas ante el SERVEL, excluyendo en la práctica la colaboración del control ciudadano que puede ser más efectivo en denunciar las infracciones. Concordantemente con ello, resulta que gran parte de los aportes privados a las campañas electorales está fuera del escrutinio ciudadano, pues las contribuciones inferiores a 20 UF, según lo dispone la ley, son anónimos y los que superan este monto son reservados, configurándose una situación de asimetría en la información entre los candidatos, partidos y la ciudadanía que no se condice con la tónica de transparencia que la ley pretendía potenciar.

Finalmente, la Ley 19.884 solo legitima como denunciantes de infracciones a sus disposiciones a los candidatos independientes y a los partidos políticos que hayan participado en la elección, prescindiendo de la colaboración del control social así como la de otros actores políticos relevantes que no hayan participado en la elección respectiva, no obstante que estos, ciertamente, tienen un interés y realizan un estrecho seguimiento de sus eventuales futuros contendores, por lo que pueden estar más atentos a las infracciones que estos puedan cometer. En ese sentido, no se entiende por qué la citada ley obvia lo que puede ser una eficaz colaboración en la fiscalización.

\section{BIBLIOGRAFÍA}

Acosta, B., ¿Por quéfracasan los países?, entrevista a J. Robinson, en Boletín Koyuntura, Instituto de Economía de la USFQU No 41, Año 5, enero, 2014, pp. 1-15. Disponible en: http:// www.usfq.edu.ec/publicaciones/koyuntura/Documents/koyuntura_2014-41.pdf [consulta: 11 de junio de 2014].

BCN, Historia de la Ley 20.840 Sustituye el sistema electoral binominal por uno de carácter proporcional inclusivo y fortalece la representatividad del Congreso Nacional, Valparaíso, 2015. Disponible en: http://www.leychile.cl/Consulta/portada_hl [consulta: 5 de agosto de 2015.

, Historia de la Ley 19.884 sobre Transparencia, límite y control de gasto electoral, Valparaíso, 2003. , Elecciones, sufragio y democracia en Chile (1810-2012). Disponible en: http://www.memoriachilena.cl/602/w3-article-3382.html [consulta: 2 de junio de 2014].

CASAS, K. y Zovatto, D, "Para llegar a tiempo: apuntes sobre la regulación del financiamiento político en América Latina”, en revista Nueva Sociedad No 225, enero-febrero de 2010, pp. 48-67. Disponible en: http://www.nuso.org/upload/articulos/3672_1.pdf [consulta: 2 junio 2014 ].

Consejo Asesor Presidencial contra los Conflictos de Interés, el Tráfico de Influencias y la Corrupción, Informe Final, Santiago, abril 2015. Disponible en: http://consejoanticorrupcion.cl/informe/ [consulta: 5 de agosto de 2015].

Contardo Díaz-Muñoz, F., "Donaciones Políticas Confidenciales”, en Valdés Prieto, S. (editor), Reforma del Estado, volumen I, Centro de Estudios Públicos, Santiago de Chile, 2000, pp. 362382. Disponible en: http://www.cepchile.cl/dms/archivo_3520_1750/refor1_09_contardo. pdf [consulta: 11 de junio de 2014]. 
Centro de Estudios de Realidad Contemporánea, Barómetro de la Política, CERC. 2014. Disponible en: http://www.cooperativa.cl/noticias/site/artic/20140123/asocfile/20140123112537/20140123102341_barometro_de_la_politica_diciembre_enero_2014. pdf [consulta: 2 junio 2014].

De la Calle Lombana, H., "La Financiación Ilícita de la Política", en Hernández Becerra, A. et al., (editores), Derecho Electoral de Latinoamérica. Memorias del II Congreso Iberoamericano de Derecho Electoral, Consejo Superior de la Judicatura, Bogotá, 2013, pp. 219-236.

El Dínamo, Servel será reestructurado en proyecto para transparentar el financiamiento de la política, noticia del 6 de noviembre de 2014. Disponible en: http://www.eldinamo.cl/pais/2014/11/06/ servel-proyecto-financimiento-politica/ [consulta: 12/08/2015].

Emol-Chile, Presidenta Bachelet firma proyecto de ley que regulará el financiamiento de la política, noticia del 15 de diciembre de 2014. Disponible en: http://www.emol.com/noticias/nacional/2014/12/15/694632/presidenta-bachelet-firma-proyecto-de-financiamiento-de-la-politica. html [consulta: 15 diciembre 2014].

Ferreira Rubio, D., "Financiamiento de los Partidos Políticos: Rendición de Cuentas y Control", en obra colectiva Reforma de los Partidos Políticos en Chile, Ed. PNUD, CEP, Libertad y Desarrollo, Proyectamerica y CIEPLAN, Santiago, 2008, pp. 377-391.

Fuentes, C., Debilidades en Nueva Ley de Financiamiento Electoral, Facultad Latinoamericana de Ciencias Sociales (FLACSO)-Chile, 2003.

InStituto Interamericano de Derechos Humanos, "Campaña Electoral” por Tuesta Soldevilla, F., en Diccionario Electoral. Disponible en: http://www.iidh.ed.cr/comunidades/redelectoral/ docs/red_diccionario/campana\%20electoral.htm [consulta: 2 de junio de 2014 ].

Jara, M. y Ramírez, P., Financiamiento ilegal de la política: Los pagos de las pesqueras, Reportaje de Investigación, Ciper, 22 de abril de 2015. Disponible en: http://ciperchile.cl/2015/04/22/ financiamiento-ilegal-de-la-politica-los-pagos-de-las-pesqueras/ [consulta: 20 de agosto de 2015].

LA TERCERA, Martelli dice que asesorías de Peñailillo fueron encargadas por el mismo exministro, noticia del 20 de junio de 2015. Disponible en: http://www.latercera.com/noticia/politica/2015/06/674635224-9-martelli-dice-que-asesorias-de-penailillo-fueron-encargadas-por-el-mismo-ex. shtml [consulta en 10 agosto de 2015].

, Empresas que financian la política, noticia del 19 de octubre de 2014. Disponible en: http://www.latercera.com/noticia/politica/2014/10/674-600874-9-empresas-que-financianla-politica.shtml [consulta 12 de agosto de 2015].

Luna, J.P., ¿Por qué es difícil pronosticar los efectos del cambio del sistema electoral?, presentación en el Seminario "Fin al Binominal, ¿cuánto cambia el escenario" organizado por el Centro de Políticas Públicas UC, Santiago, 5 de junio de 2015. Disponible en: http://politicaspublicas.uc.cl/seminario/seminario-fin-al-binominal-cuanto-cambia-el-escenario/ [consulta: 5 de agosto de 2015].

Mann, Th., "Dilemas de las Regulaciones del Financiamiento Político", en Valdés Prieto, S. (editor), Reforma del Estado, Volumen I., Centro de Estudios Públicos, Santiago de Chile, 2000, pp. 2-22. Disponible en: http://www.cepchile.cl/dms/archivo_3512_1742/refor1_01_mann. pdf [consulta: 11 de junio de 2014].

Matamala, D., La lista completa: la verdad sobre las 1.123 empresas que financian la política en Chile, Reportaje de Investigación, Ciper, 23 de abril de 2015. Disponible en: http://ciperchile. cl/2015/04/23/la-lista-completa-la-verdad-sobre-las-1-123-empresas-que-financian-la-politica-en-chile/ [consulta 12 de agosto de 2015].

Monje Reyes, P., La Ley de Financiamiento de Gasto Electoral. Un Análisis Crítico desde la Gestión Pública, en Agenda Pública, Año IV-No 6, 2005, pp. 25-32. Disponible en: http://www. agendapublica.uchile.cl/n6/monje.pdf [consulta: 11 de junio de 2014]. 
Navia, P., "Modernización del Estado y Financiamiento de la Política: Una Crisis que se Transformó en Oportunidad", en Stefoni, C. (editora), Chile 2003-2004. Los Nuevos Escenarios (inter) nacionales, Flacso, Chile, 2004.

Palda, F., "Regulación del Financiamiento Electoral en Chile: Lecciones de Canadá y los Estados Unidos”, en Valdés Prieto, S. (editor), Reforma del Estado, Volumen I, Centro de Estudios Públicos, Santiago, 2000. Disponible en: http://www.cepchile.cl/dms/archivo_3517_1747/ refor1_06_palda.pdf [consulta: 11 de junio de 2014].

Partarrieu, B., El $90 \%$ de los aportes privados a las campañas políticas es secreto, Reportaje de Investigación, Ciper, 8 de octubre de 2014. Disponible en: http://ciperchile.cl/2014/10/08/ el-90-de-los-aportes-privados-a-las-campanas-politicas-es-secreto/ [consulta 10/08/2015].

Rojas, H., Mecanismos de Fiscalización Ciudadana respecto de la (Falta de) Transparencia de los Gastos Electorales: Aportes al Debate sobre la Insuficiencia e Ineficacia de la Ley 19.884, en Agenda Pública, Año IV-Nº 6, 2011, pp. 8-11. Disponible en: http://agendapublica.uchile.cl/n6/ mec-fisc.pdf [consulta: 11 de junio de 2014].

Rosales, C.M., "El Control Jurisdiccional del Gasto Electoral en los Estados Unidos de América", en González Oropeza, M. y Cienfuegos Salgado, D. (coordinadores), Cuestiones y Reflexiones Político-Electorales, Ed. H. Congreso del estado de Guerrero, Congreso del estado de Coahuila, Poder Judicial del estado de Durango y Universidad Autónoma de Guerrero, México, 2011, pp. 415-427. Disponible en: http://biblio.juridicas.unam.mx/libros/7/3031/23.pdf [consulta: 11 de junio de 2014].

Santano, M.C., Una breve retrospectiva sobre la financiación de los partidos políticos en Alemania, en Revista Paraná Eleitoral v. 2 No 2, 2013, pp. 215-228. Disponible en: http://www. justicaeleitoral.jus.br/arquivos/tre-pr-parana-eleitoral-2013-volume-2-revista-2-artigo3-ana-claudia-santano [consulta: 11 de diciembre de 2014].

Sánchez González, S., La Financiación de los Partidos Políticos en los Estados Unidos, en Teoría y Realidad Constitucional, núm. 6, 2º semestre, UNED, 2001, pp. 71-81.

San Martín, E., Sistema Binominal versus Coeficiente D'Hont ¿Cuán diferentes son como métodos de asignación parlamentaria?, Seminario "Fin al Binominal, ¿cuánto cambia el escenario", Centro de Políticas Públicas UC, presentación del 5 de junio de 2015. Disponible en: http:// politicaspublicas.uc.cl/seminario/seminario-fin-al-binominal-cuanto-cambia-el-escenario/ [consulta: 5 de agosto de 2015].

Servel, Manual de Gasto Electoral. Elecciones Presidencial, Parlamentarias y Consejeros Regionales 2013, Santiago, 2013. Disponible en: http://www.24horas.cl/politica/decisionfinal/article904537. ece/BINARY/Manual+Gasto+Electoral + 2013 [consulta: 2 de junio de 2014].

Conocimiento, Tramitación y Resolución. Procedimientos Administrativos Sancionatorios. Artículo 51 Ley 19.884, Santiago, s/f.

TRANSPARENCy International Chile, Impacto de la Corrupción en Diferentes Sectores e Instituciones (todos los países). Disponible en: http://www.chiletransparente.cl/wp-content/uploads/2013/07/ Barómetro-2013-v-1-0.pdf [consulta: 2 de junio de 2014).

TVN 24 Horas, Peñailillo encargó sus propios informes y definió sus honorarios en la empresa de Martelli. Disponible en: http://www.24horas.cl/politica/penailillo-encargo-sus-propios-informes-ydefinio-sus-honorarios-en-la-empresa-de-martelli-1700432 [consulta: 10 de agosto de 2015]. , Presidente de la CPC en Estado Nacional: Hay que diferenciar las actitudes del empresariado, en programa Estado Nacional del 28 de septiembre de 2014. Disponible en: http://www.24horas. cl/programas/estadonacional/presidente-de-la-cpc-en-estado-nacional-hay-que-diferenciarlas-actitudes-del-empresariado-1430878 [consulta: 10/08/2015].

Urcullo Cossío, L.G. y Moya Díaz, E.J., Control del Financiamiento y Gasto Electoral en Chile, Capítulo Chileno de Transparencia Internacional, Chile Transparente, Santiago, 2009. 
V.V.A.A., Promoviendo el Fortalecimiento de los Procesos y Sistemas Electorales en el Hemisferio: el Financiamiento de la Política, los Registros Electorales, y la Educación Cívica-Electoral, Primera Jornada Interamericana Electoral, Organización de los Estados Americanos, México, 2008. Disponible en: http://www.oas.org/sap/temp/Archivos\%20actualización\%20noviembre\%20 DECO/Publicaciones/Publicación\%20I\%20Jornadas\%20ESP.pdf [consulta: 2 de junio de 2014 ]. 